\title{
Especificidades do conhecimento do professor de matemática na e para a formação: uma discussão em torno do programa de complementação pedagógica
}

\author{
Marlova Estela Caldatto' (D) \\ Carlos Miguel Ribeiro"
}

\section{RESUMO}

Neste artigo discutimos os conhecimentos privilegiados pelo projeto de formação inicial de professores de matemática desenvolvido por uma universidade no âmbito da política pública "formação pedagógica para graduados não licenciados". Assim, mediante um estudo quali-quantitativo, analisamos dados extraídos de documentos relativos à implementação, entre 2011 e 2017, de 19 turmas dessa política. As análises evidenciam um distanciamento entre a formação desenvolvida, as prescrições jurídicas vigentes e os conhecimentos tidos pela literatura como necessários para a prática do professor de matemática, além do aprimoramento da histórica cisão entre os conhecimentos pedagógicos, matemáticos e a prática escolar.

\section{PALAVRAS-CHAVE}

conhecimento especializado do professor de matemática; formação inicial; programa de complementação pedagógica. 


\title{
SPECIFICITIES OF THE MATHEMATICS TEACHER'S KNOWLEDGE IN AND FOR TRAINING: A DISCUSSION ON THE PEDAGOGICAL COMPLEMENTATION PROGRAM
}

\begin{abstract}
In this article we discuss the privileged knowledge of the project of initial formation of teachers of mathematics developed by a university within the scope of the public policy "pedagogical training for graduates not graduated". Thus, through a qualitative-quantitative study, we analyze data extracted from documents related to the implementation, between 2011 and 2017, of 19 classes of this policy. The analyses show a distancing between the training developed, the legal prescriptions in force and the knowledge acquired by the literature as necessary for the practice of the mathematics teacher, as well as the improvement of the historical split between pedagogical, mathematical, and school practice knowledge.

\section{KEYWORDS}

specialized knowledge of the mathematics teacher; initial formation; pedagogical complementation program.
\end{abstract}

\section{ESPECIFICIDADES DEL CONOCIMIENTO DEL PROFESOR DE MATEMÁTICAS EN Y PARA LA FORMACIÓN: UNA DISCUSIÓN EN TORNO AL PROGRAMA DE COMPLEMENTACIÓN PEDAGÓGICA}

\section{RESUMEN}

En este artículo discutimos el conocimiento privilegiado por el proyecto de formación inicial de profesores de matemática desarrollado por una universidad en el ámbito de la política pública "formación pedagógica para graduados no licenciados". Así, a través de un estudio cualitativo y cuantitativo, analizamos datos extraídos de documentos relacionados con la implementación, entre 2011 y 2017, de 19 clases de esa política. Los análisis evidencian un distanciamiento entre la formación desarrollada, las prescripciones jurídicas vigentes y los conocimientos tenidos por la literatura como necesarios para la práctica del profesor de matemáticas, además del perfeccionamiento de la histórica escisión entre los conocimientos pedagógicos, matemáticos y la práctica escolar.

\section{PALABRAS CLAVE}

conocimiento especializado del profesor de matemáticas; formación inicial; programa de complementación pedagógica. 


\section{INTRODUÇÃO}

Um ponto recorrente na crítica aos processos formativos de professores, especialmente dos que ensinam matemática, é a desarticulação entre "dois aspectos indissociáveis da função docente: a forma e o conteúdo" (Saviani, 2009, p. 151). Essa problemática é histórica e remonta à década de 1930, à criação das primeiras universidades brasileiras e das licenciaturas (Caldatto e Pavanello, 2015; Moreira e David, 2005), cursos cuja estrutura curricular, conhecida como “ $3+1$ ”, destinava três anos às disciplinas específicas de conteúdo (matemático) e um ano às disciplinas de natureza pedagógica para o bacharelado (Moreira, 2012). Esse modelo formativo, que ainda vigora no Brasil, é fortemente criticado pelos estudiosos por não promover um mínimo de articulação entre essas duas dimensões e favorecer a polarização dos conhecimentos profissionais, sendo a dimensão matemática supervalorizada em relação à pedagógica (Moreira, 2012; Moreira e David, 2005).

$\mathrm{Na}$ década de 1980, iniciou-se o movimento de inserção de "disciplinas integradoras" nos currículos das licenciaturas - no caso da matemática, intitulam-se, por exemplo, didática da matemática, prática de ensino da matemática, entre outras —, visando à articulação entre as dimensões do modelo “ $3+1$ ”. Entretanto, tal cenário formativo, de acordo com Oliveira e Fiorentini (2018, p. 9), originou uma nova cisão, agora entre as disciplinas de conteúdo e as integradoras, uma vez que o objeto de estudos de ambas "parece ser ainda difuso e pouco compreendido em suas múltiplas dimensões" por uma parcela dos formadores de professores de matemática.

Apesar de nos remetermos, assim como boa parte da literatura que estuda a formação docente, aos licenciados como sendo, aparentemente, os únicos juridicamente assegurados para atuar na docência na educação básica, ${ }^{1}$ figura nas escolas um grande contingente de profissionais que estão habilitados e legalmente amparados para o exercício da docência, mas não frequentaram curso de licenciatura, e sim cursos de complementação pedagógica ${ }^{2}$ (PROFOP) (Zocolotti, 2015). Essa modalidade formativa constituiu-se legalmente em 1996, por meio da promulgação da Lei de Diretrizes e Bases da Educação (LDB), que estabeleceu a formação em nível superior como condição necessária para a atuação na educação básica, podendo ela ser obtida por meio de cursos de licenciatura plena ou de "programas de formação pedagógica para portadores de diplomas de educação superior que queiram se dedicar à Educação Básica” (Brasil,1996).

Em consequência da LDB, também foram publicados pelo Conselho Nacional de Educação (CNE) documentos balizadores da formação de professores desenvolvida em âmbito nacional, entre eles: as "Diretrizes Curriculares Nacionais para a formação de professores em nível superior, curso de licenciatura, de graduação plena" (resoluções CNE/CP n. 1/2002 e CNE/CP n. 2/2002), as "Diretrizes Curriculares Nacionais para os Cursos de Matemática, Bacharelado e Licenciatura”

1 Tal termo, doravante, será interpretado como sinônimo da expressão "anos finais do ensino fundamental e ensino médio".

2 No decorrer do texto, essa expressão será equivalente à sentença "programas especiais de formação pedagógica de docentes para as disciplinas do currículo do ensino fundamental, do ensino médio e da educação profissional em nível médio" e "Programa Especial de Formação Pedagógica”, sendo representada pela sigla PROFOP. 
(resolução CNE/CES n. 3/2003) e a resolução CNE/CP n. 2/1997, que dispõe exclusivamente sobre PROFOP. ${ }^{3}$

A resolução CNE/CP n.2/1997, ao corporificar a LDB, também regulamentou uma modalidade formativa relacionada diretamente ao déficit de professores que permeava (e ainda permeia, em algumas circunstâncias) o cenário educativo brasileiro, o PROFOP, definido como um programa de caráter especial, "destinado a portadores de diploma de nível superior, em cursos relacionados à habilitação pretendida [em nível equivalente à de licenciado], que ofereçam sólida base de conhecimentos na área de estudos ligada a essa babilitação" (Brasil, 1997, p. 1, grifos nossos).

Ainda em decorrência da LDB, o Plano Nacional de Educação (PNE) fixou como um de seus objetivos (para ser efetivado em até 10 anos) a formação específica em nível superior de "70\%" dos professores que atuavam no ensino fundamental e de "todos" os que atuavam no ensino médio (Brasil, 2001, p. 67). Como efeito, surge uma "demanda de 1,6 milhões de professores brasileiros em exercício sem essa titulação" e a "necessidade de aumento da oferta de oportunidades ou centros de formação” (Fiorentini, 2008, p. 46).

Mediante esse cenário político-educacional, Gatti e colaboradoras (Gatti e Barretto, 2009; Gatti, Barretto e André, 2011), em um trabalho inédito, mapearam e analisaram políticas relativas à formação inicial e continuada que visam à melhoria do desempenho escolar dos alunos. Particularmente em relação à formação inicial, analisaram a legislação federal e os programas federais associados, além de, aproximadamente, 14 mil cursos de licenciatura e 7 cursos de "formação pedagógica para não licenciados", sendo esses últimos oferecidos na Região Nordeste do país e no âmbito da Universidade Aberta do Brasil. Os resultados desse mapeamento mostram que as formações na área disciplinar e na pedagógica são "dois universos que não se comunicam” (Gatti, Barretto e André, 2011, p. 95), revelando que a crise no sistema formativo de docentes no Brasil está sendo "camuflada" e, ao que parece, ainda não assumiu proporções suficientes "para provocar a busca de alternativas institucionais e curriculares mais condizentes com as necessidades formativas relativas aos professores em conjugação com as necessidades educacionais e de aprendizagem das novas gerações" (Gatti, Barretto e André, 2011, p. 96-97).

Nesse contexto, interessamo-nos, de modo particular, pela formação de professores de matemática desenvolvida por uma universidade federal localizada na Região Sul do país, no âmbito da política pública PROFOP, e estabelecemos as seguintes questões investigativas como balizadoras deste artigo: Qual a natureza dos conhecimentos que compuseram o processo de formação inicial de professores de matemática desenvolvido por uma Instituição de Ensino Superior (IES) pública no

3 Em 2015, as resoluções CNE/CP n. 2/1997, CNE/CP n. 1/2002 e CNE/CP n. 2/2002 foram revogadas pela resolução $\mathrm{CNE} / \mathrm{CP}$ n. 2/2015, que define as "Diretrizes Curriculares Nacionais para a Formação Inicial em Nivel Superior e para a Formação Continuada de Profissionais do Magistério para a Educação Básica”. Tal resolução, que atualmente vigora, prescreve um processo formativo que articule os conhecimentos das distintas áreas de atuação profissional do professor, podendo, em nível inicial, ser desenvolvido tanto via licenciatura quanto via "cursos de formação pedagógica para graduados", sendo esses últimos considerados de caráter emergencial e provisório. 
contexto do PROFOP? Esse processo formativo contempla as prescrições contidas nos dispositivos jurídicos vigentes e os conhecimentos tidos pela literatura como essenciais para a prática do docente de matemática ao ensinar essa área do conhecimento em âmbito escolar? Tendo em vista esses questionamentos, apresentamos, na sequência, o percurso metodológico da pesquisa, a fundamentação teórica e as análises produzidas sobre a natureza dos conhecimentos disseminados e privilegiados pelo PROFOP, e, à guisa de conclusão, apresentamos nossas considerações sobre a problemática em discussão no artigo.

\section{PERCURSO METODOLÓGICO DA INVESTIGAÇÃO}

O objetivo desta pesquisa foi caracterizar e analisar os conhecimentos que integralizaram o processo de formação inicial de professores de matemática desenvolvido por uma universidade federal entre os anos de 2011 e 2017, no âmbito da política pública PROFOP. Discutiremos os conhecimentos privilegiados pelas disciplinas desenvolvidas no PROFOP e aqueles associados aos cursos de graduação que foram considerados portadores de uma "sólida base de conhecimentos" em matemática (provenientes da primeira graduação do egresso) (Brasil, 1997), buscando elucidar, por um lado, se (e até que ponto) esse processo formativo atendeu às prescrições jurídicas vigentes e, por outro, se a dicotomia entre a forma e o conteúdo foi superada, na expectativa de serem contempladas as dimensões especializadas da formação do professor de matemática evidenciadas pelas pesquisas produzidas na área de educação.

Tal objetivo de pesquisa justifica-se porque está associado a uma política que visa à "certificação" docente, uma das medidas utilizadas para avalizar o conhecimento e a qualidade desses profissionais (Hill e Ball, 2009). Pretendemos, assim, discutir se os projetos e políticas implementadas aproximam-se dos anseios e necessidades formativas reais dos professores (Nacarato, 2016) abordando um tema pouco investigado pela literatura brasileira nos últimos 30 anos: as macropolíticas relativas aos docentes da educação básica, de modo especial o PROFOP (André, 2010; Gatti, 2014; Zocolotti, 2015).

No processo de elaboração do trabalho, foram fixados alguns parâmetros metodológicos como balizadores da pesquisa. Um deles foi o emprego da perspectiva quali-quantitativa como delineadora do processo analítico, uma vez que nos pautamos na análise documental e de conteúdo, da estatística descritiva — desvio padrão $(d p)$, amplitude $(\Delta)$ - e dos testes de Kruskall-Wallis e Tukey para tabular, apresentar e discutir os dados.

No que se refere aos dados em análise, são originários de "Projetos de Abertura" e de "Relatórios de Avaliação Final" de $19^{4}$ turmas do PROFOP, implementadas pela IES entre os anos de 2011 e 2017, e das resoluções n. 28/2011 e n.

$4 \mathrm{Na}$ coleta dos dados, as turmas investigadas tinham tanto o "Projeto de Abertura de Turma" quanto o "Relatório de Avaliação Final", principal instrumento de avaliação do PROFOP pela IES, já aprovados pelo Conselho de Graduação e Educação Profissional (COGEP) e pela Câmara de Bacharelados e Licenciaturas do "Relatório de Avaliação Final da Turma”. Os documentos encontravam-se disponíveis no site da instituição para consulta pública. 
29/2011 - COGEP (UTFPR 2011a, 2011b). O recorte temporal foi determinado pelo ano de publicação das nominadas resoluções, 2011, e pelo ano da coleta dos dados da pesquisa, 2017. A adoção de tais documentos oficiais — produzidos pela IES - no processo de coleta dos dados ocorreu em virtude de documentos dessa natureza se configurarem como "a fonte mais fidedigna de dados", além de se referirem a atos individuais ou coletivos cujo alcance pode ser "municipal, estadual ou nacional" (Marconi e Lakatos, 2017, p. 193). Além disso, apresentam um conjunto de dados e informações que, após "organização e tratamento analítico" (Santos, 2007, p. 32), passaram a caracterizar as turmas ofertadas no PROFOP, como em relação à natureza e à finalidade do curso, grade e ementas, critérios de admissão de candidatos à certificação equivalente à de licenciado, entre outras.

No que se refere aos testes de Kruskall-Wallis e Tukey, foram usados para avaliar se "há" e "qual é" a diferença entre o número de habilitados por áreas no nível de 5\%. Assim, serão apresentadas as expressões "p-valor" e " $F$ ", que representam, respectivamente, a probabilidade de rejeitar a hipótese de igualdade do número de habilitados e a estatística desse teste que está relacionada à probabilidade p-valor (Costa, 2015).

Com relação à análise do conteúdo desenvolvida, foram categorizados elementos das ementas e disciplinas que culminaram na titulação equivalente à de licenciado em matemática de egressos do PROFOP, de acordo com os domínios e subdomínios da Mathematics Teachers Knowledge Base (Figura 1), originária da

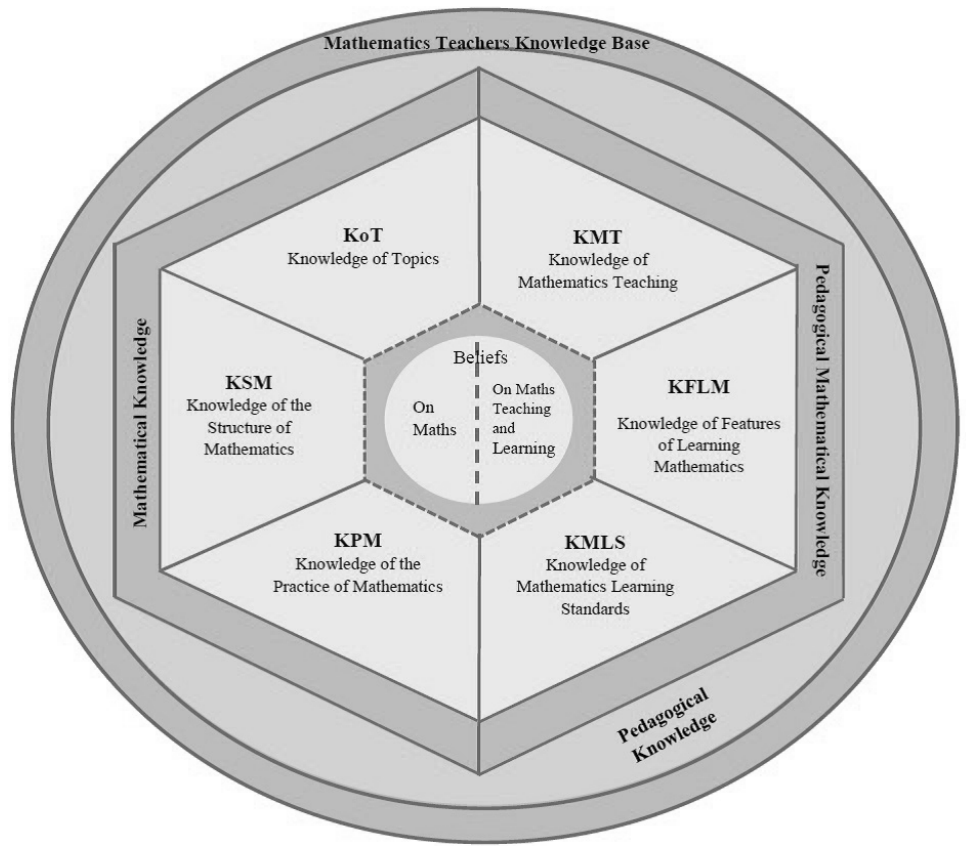

Figura 1 - Mathematics Teachers Knowledge Base: domínios e subdomínios para a formação de professores de matemática. Fonte: Banco de dados da pesquisa (2018). 
complementação entre o Knowledge Base e o Mathematics Teacher's Specialised Knowledge (MTSK), discutido na sequência. Além disso, outro elemento importante no processo analítico foram a resolução $\mathrm{CNE} / \mathrm{CP}$ n. 02/1997 e os documentos derivados dela, uma vez que, apesar de a resolução CNE/CP n. 02, de $1^{\circ}$ de julho de 2015 , no ato da coleta de dados já estar em vigor, optamos por não adotá-la como parâmetro de análise, uma vez que as turmas do PROFOP ora analisadas foram propostas, implementadas e avaliadas com base na resolução CNE/CP n. 02/1997.

\section{MATHEMATICS TEACHERS KNOWLEDGE BASE E AS ESPECIFICIDADES DO CONHECIMENTO DO PROFESSOR QUE ENSINA MATEMÁTICA}

O interesse no conhecimento profissional do professor de matemática ganhou relevância (nacional e internacional) nas últimas décadas, e uma das vertentes mais proeminentes é a dos estudos desenvolvidos no âmbito do reconhecimento e da identificação do conbecimento do professor de matemática que efetivamente impacta na qualidade do ensino (Scheiner et al., 2017), baseados em distintos modelos analíticos-explicativos derivados do Knowledge Base (Shulman, 1986, 1987).

O Knowledge Base configura-se, do ponto de vista contemporâneo, como uma das mais influentes categorizações do conhecimento profissional do professor (Carrillo-Yañez et al., 2018; Krauss e Blum, 2013) em nível internacional, especialmente por definir/identificar/introduzir o Pedagogical Content Knowledge (PCK), que se refere ao conhecimento pedagógico intimamente articulado ao conteúdo objeto de ensino. Além do PCK, essa base de conhecimentos compõe-se pelas seguintes categorias: Content Knowledge; Curriculum Knowledge; General Pedagogical Knowledge; Knowledge of Learners and their Characteristics; Knowledge of Educational Contexts; Knowledge of Educational ends, Purposes, and Values, and their Philosophical and Historical Grounds (Shulman, 1986, 1987).

Fundamentados no trabalho de Shulman, na área de matemática foram propostos distintos modelos analítico/explicativos, por exemplo: "Psychological Topology of Teachers' Professional Knowledge” (Bromme, 1993), "Knowledge Quartet" (Rowland e Turner, 2007), "Mathematical Knowledge for Teaching" (MKT) (Ball, Thames e Phelps, 2008), "Proficient Teaching of Mathematics" (Schoenfeld e Kilpatrick, 2008), "Professional Competence of Teachers, Cognitively Activating Instruction, and the Development of Students' Mathematical Literacy" (Baumert e Kunter, 2013), "Didactic-Mathematical Knowledge" (Pino-Fan, Assis e Castro, 2015), "Teacher Education and Development Study: Learning to Teach Mathematics"(Kaiser et al., 2017), "Mathematics Teacher's Specialised Knowledge" (MTSK) (Carrillo-Yañez et al., 2018).

Um dos principais resultados desses estudos foi a identificação da estreita vinculação entre o ensino de alta qualidade e um conhecimento profissional sofisticado, relacionado a um conhecimento profundo do conteúdo que o professor objetiva ensinar (Charalambous e Litke, 2018). Nesse sentido, e considerando que todo o conhecimento do professor é especializado - tanto no que se refere ao PCK 
quanto ao relativo ao conhecimento do conteúdo - , assumimos nesta pesquisa as perspectivas do MTSK e do Knowledge Base, com a finalidade de ser apresentado um modelo da base dos conhecimentos do professor de matemática.

O MTSK corresponde a uma conceitualização do conhecimento do professor que emergiu de uma reinterpretação do MKT (Ball, Thames e Phelps, 2008), do PCK, do Content Knowledge e Curriculum Knowledge (Shulman, 1986), que é voltada para a discussão dos conhecimentos que se vinculam diretamente ao ensino da matemática pressupondo que existem conhecimentos de naturezas distintas (Figura 2), interrelacionados e suficientes para o desenvolvimento de uma prática docente integrada e geradora de diversos e potentes contextos de aprendizagem para os alunos (Zakaryan e Ribeiro, 2018).

Tendo em conta que o conhecimento especializado do professor não é simplesmente um conglomerado de vários campos, mas configura-se como uma integração deles - que deve ocorrer durante as formações inicial e continuada -, no MTSK se consideram os domínios de conhecimento, Mathematical Knowledge (MK), que se subdivide em Knowledge of Topics (KoT), Knowledge of the Structure of Mathematics (KSM) e Knowledge of the Practice of Mathematics (KPM), e PCK, que é subdividido em Knowledge of Mathematics Teaching (KMT), Knowledge of Features of Learning Mathematics (KFLM) e Knowledge of Mathematics Learning Standards (KMLS). ${ }^{5}$

Dado que o MTSK apresenta uma conceitualização do conhecimento exclusivo da prática do professor de/que ensina matemática e que a prática de todo professor também exige um conjunto de conhecimentos pedagógicos, nominados aqui como Pedagogical Knowledge (PK) - não relacionados diretamente com os "conteúdos" escolares -, quando situamos o MTSK na formação integral do professor e nas disciplinas que a compõem, a consideração desse conjunto conhecimentos pedagógicos torna-se imprescindível.

Assim, podemos considerar um modelo analítico que permita guiar o foco de análise da formação do professor de matemática originário de uma mutua complementação entre o MTSK e o PK, sendo esse último representado pela conjunção dos conhecimentos que permeiam e são comuns ao processo formativo do professor de qualquer área de conhecimento (como biologia ou química) e que, portanto, não se vinculam às especificidades do ensino e da aprendizagem das áreas de conhecimento. Assim, o PK é aqui entendido, com base no trabalho de Shulman (1987), como uma composição entre:

- General Pedagogical Knowledge;

- Knowledge of Learners and their Characteristics;

- Knowledge of Educational Contexts;

- Knowledge of Educational ends, Purposes, and Values, and their Philosophical and Historical Grounds.

5 Para mais informações sobre os conteúdos de cada um dos subdomínios, consultar, por exemplo, Zakaryan e Ribeiro (2018). 
Nessa conjuntura, e especificamente no âmbito da matemática, podemos assumir a Figura 2 como uma forma de representação dessa articulação entre as especificidades (MTSK) e as generalidades (PK) do conhecimento do professor, que ilustra os elementos geradores e necessários em formações (inicial e continuada) que atendam efetiva e integralmente às demandas dos professores de (que ensinam) matemática. Note-se que essa forma de entender e representar a imprescindível complementação entre o Knowledge Base e o MTSK, desenvolvida e nominada por nós como Mathematics Teachers Knowledge Base, visa contribuir para um refinamento do foco de atenção (teórico e metodológico) no/para o entendimento da estrutura e dos objetivos dos cursos de formação. Assim, por meio do MTKB, busca-se contribuir para a promoção de uma formação focada no desenvolvimento integral do conhecimento do professor de matemática, de modo que promova a articulação entre a "forma e o conteúdo" (Saviani, 2009), atendendo às diversas demandas emergentes das práticas desse profissional, particularmente as voltadas para a melhora das aprendizagens e resultados matemáticos dos alunos.

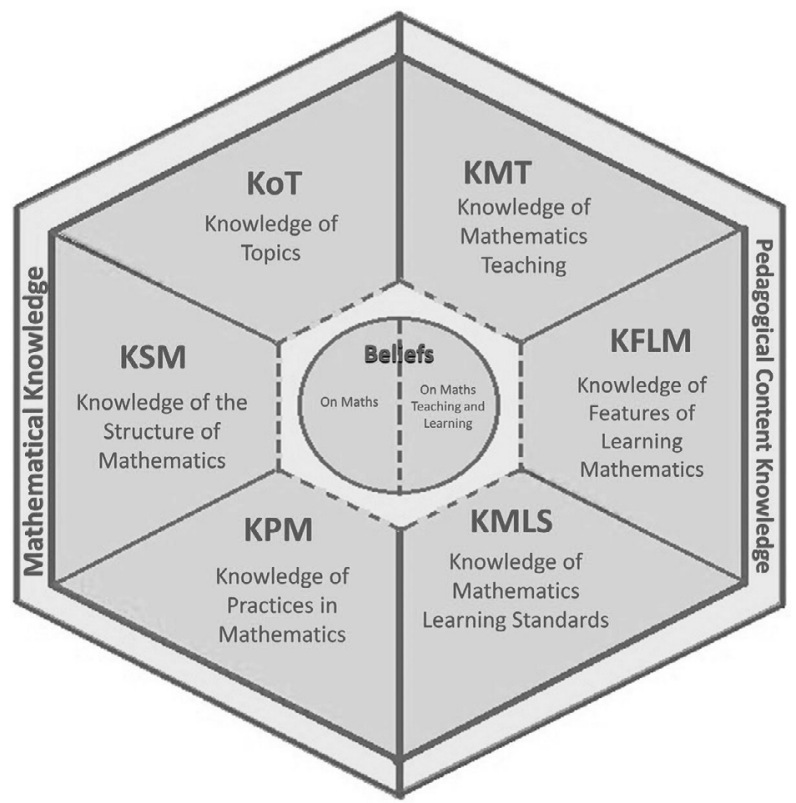

Figura 2 - Domínios e subdomínios do MTSK.

Fonte: Carrillo-Yañez et al. (2018, p. 6).

\section{CARACTERIZAÇÃO DO PROFOP: APRESENTAÇÃO DOS DADOS, ANÁLISES E RESULTADOS}

Conforme referido, a resolução CNE/CP n. 02/1997 dispõe sobre o PROFOP, programa cujo objetivo principal é "suprir a falta de professores habilitados, em determinadas disciplinas e localidades, em caráter especial” (Brasil, 1997, p. 1). 
Assim, a implementação de tais programas pretende sanar, em caráter provisório e pontual (considerando as demandas regionais/locais), a falta de professores em determinadas disciplinas do currículo escolar, uma vez que a via de acesso à docência na educação básica deve ser a licenciatura.

Tal resolução prevê, sinteticamente, os parâmetros aos quais os PROFOP deveriam atender, observados até o ano de 2017, tais como objetivos, características da estruturação curricular, carga horária mínima do curso e atribuições da IES promotora. Além de enfatizar a importância da vinculação entre a formação pedagógica e o domínio dos conteúdos específicos, defendendo uma forte relação entre a teoria e a prática do professor ao ensinar os conteúdos escolares.

A resolução CNE/CP n. 02/1997 corporifica-se internamente na IES por meio dos documentos "Regulamento do Programa Especial de Formação Pedagógica" (resoluções n. 28/11 e n. 72/12 - COGEP) e "Orientações para a Elaboração do Projeto de Abertura de Turma Programa Especial de Formação Pedagógica" (resolução n. 29/11 - COGEP). Esses documentos balizam o planejamento e a organização do referido programa prevendo os recursos humanos, financeiros, didático-pedagógicos (rol de disciplinas, ementário, carga horária), exigências para o ingresso em uma turma, áreas de habilitação do PROFOP na IES, entre outras questões. Sendo o PROFOP um mecanismo utilizado pela IES "para habilitar portadores de diploma de nível superior, para o exercício do Magistério em disciplinas do Currículo que integram o segundo ciclo do ensino fundamental, o ensino médio e a educação profissional em nível médio, em diferentes sistemas de ensino" (UTFPR, 2011a, p. 4), organizado de acordo com número de turmas, período e local de realização.

Nesse panorama regulamentar e jurídico é que as 19 turmas em análise foram implementadas, sendo habilitados, entre 2011 e 2017, em média, 30,8 alunos ( $d p=5,4$ e $\Delta=16$ ), totalizando 584 professores (Gráfico 1) para atuarem, não simultaneamente, em 26 áreas distintas do conhecimento. Desse total, 21\% habilitaram-se para atuar em disciplinas vinculadas à educação profissional, enquanto $79 \%$ habilitaram-se em disciplinas vinculadas à educação básica (arte, biologia, ciências, física, língua espanhola, língua inglesa, língua portuguesa, matemática e química).

Os dados apresentados no Gráfico 1 revelam que, enquanto o somatório das habilitações concedidas nas áreas do conhecimento de construção civil, ciências, alimentos, edificações, psicologia, pecuária, mecânica e logística representa 1,35\% do total de habilitados, o somatório das habilitações concedidas nas áreas de física, biologia, matemática e química representa $75,3 \%$ do total de candidatos habilitados, e somente a área de matemática habilitou $35 \%$ do total alunos das turmas do PROFOP analisadas. Essa aparente diferença entre os conjuntos de habilitados é corroborada pelos dados originados do teste de hipóteses para comparação de duas proporções, de modo que é possível indicar, no nível de 5\% de significância, que foram conferidas mais habilitações nas áreas de física, biologia, matemática e química do que nas demais áreas ( $\mathrm{p}$-valor $<0,05, \mathrm{~F}=24,47$ ). Da mesma forma, ao avaliar o cômputo de habilitados em matemática, o número é estatisticamente superior ao de habilitados em química ( $\mathrm{p}$-valor $<0,05, \mathrm{~F}=5,97$ ) e, por conseguinte, ao número de habilitados nas demais áreas do conhecimento discriminadas no Gráfico 1 (desde biologia até logística). 


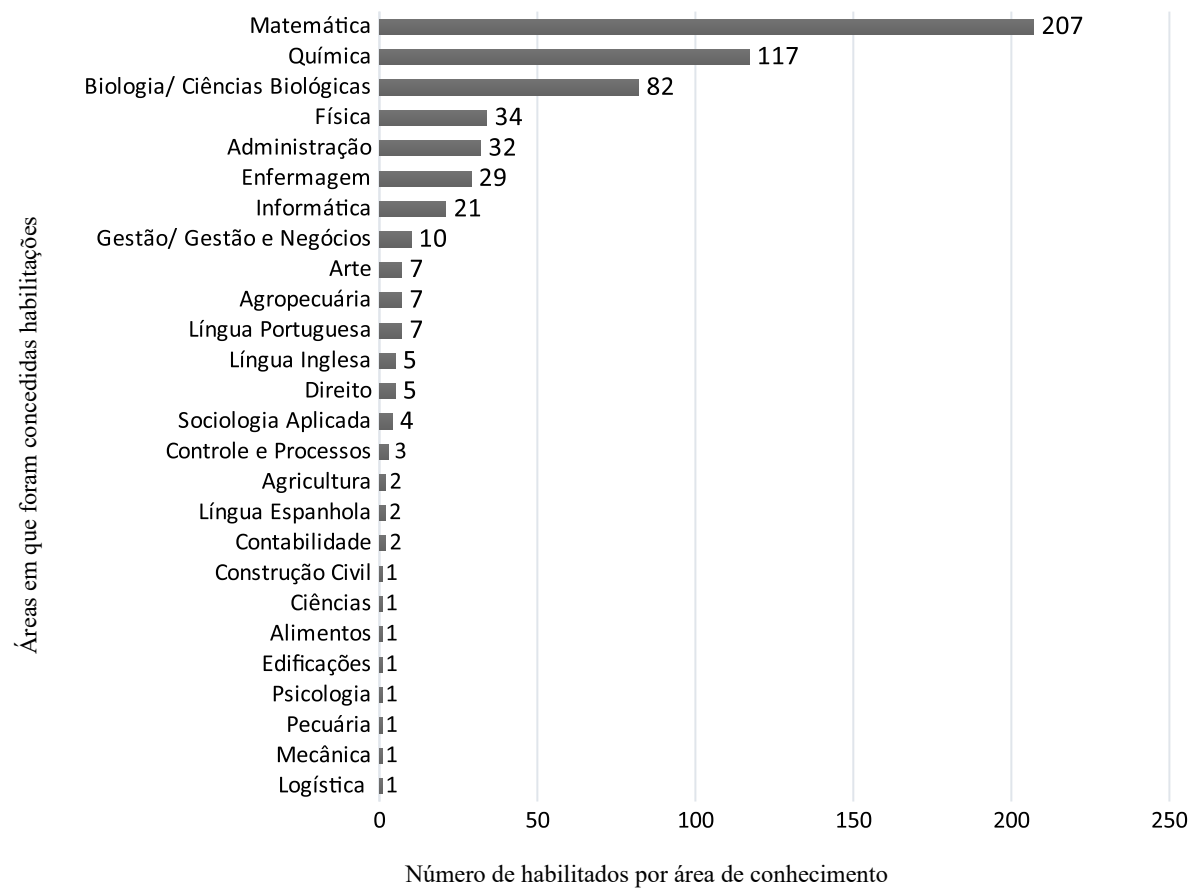

Gráfico 1 - Número de alunos habilitados por áreas do conhecimento no decorrer da implementação das 19 turmas. Fonte: Banco de dados da pesquisa (2018).

Elaboração dos autores.

No que se refere às 19 turmas analisadas, constatamos que em cada uma delas, em média, 11 candidatos obtiveram habilitação equivalente à de licenciado em matemática $(d p=4,05$ e $\Delta=15)$, número que se desdobra em termos da frequência de habilitados por turma, de acordo com os intervalos especificados na Tabela 1 , onde $f i$ representa o número de turmas que concederam habilitação em licenciatura em matemática, e $L i$ e $L s$ representam, respectivamente, os limites inferiores e superiores dos intervalos.

Tabela 1 - Frequência de número de habilitados em matemática por turmas.

\begin{tabular}{c|c|c}
\hline$L i$ & $L s$ & $f i$ \\
\hline 2 & 6 & 2 \\
\hline 7 & 10 & 5 \\
\hline 11 & 14 & 6 \\
\hline 15 & 18 & 6 \\
\hline Total de turmas & & 19 \\
\hline
\end{tabular}

Fonte: Banco de dados da pesquisa (2018).

Elaboração dos autores. 
Com base na Tabela 1, é possível aferirmos que mais de $63 \%$ das turmas ofertadas forneceram 11 ou mais habilitações equivalentes à de licenciado em matemática. Esse dado, 11 habilitações por turma, quando associado ao número de vagas ofertadas por turma e explicitado nos "Projetos de Abertura", 44 vagas, representa um mínimo de $25 \%$ do total das vagas disponíveis. Ou seja, do total de vagas ofertadas pelo PROFOP, 25\% delas culminaram na habilitação de um professor para ministrar matemática na educação básica.

Ainda em conformidade com os dados expostos, é possível notar uma variação grande do número de habilitados por área, de modo que a área de matemática se destaca consideravelmente por ser a que mais forneceu habilitações e a única que habilitou candidatos em todas as turmas analisadas. Diante dessa observação, propusemo-nos a caracterizar e discutir a formação dos habilitados em matemática desenvolvida no âmbito do PROFOP, uma vez que uma parcela considerável das habilitações concedidas está associada a essa área do conhecimento.

Tendo em conta essa conjuntura, inserimos na discussão o conjunto de conhecimentos adquiridos pelos habilitados para ministrar matemática por meio de formação no PROFOP, tanto no decorrer do curso quanto anteriormente ao seu ingresso no programa (graduação apresentada no processo de seleção dos candidatos). Iniciamos a análise pelo rol de disciplinas do PROFOP considerando que, de acordo com as resoluções n. 28/2011 e n. 72/2012 (COGEP), todas as turmas que forem ofertadas na IES, independentemente do público ao qual forem destinadas (portadores de graduações nas áreas de engenharia, administração, agronomia etc.) e da certificação desejada por meio do PROFOP (matemática, química, língua portuguesa), devem possuir o mesmo formato (grade e ementário).

Ademais, de acordo com as supramencionadas resoluções, tais turmas podem ser habilitadas simultaneamente nas áreas de matemática, física, biologia, química, língua portuguesa, língua estrangeira moderna e disciplinas de cunho profissionalizante. Ou seja, por meio de um mesmo momento formativo, uma turma do PROFOP pode habilitar-se em distintas áreas do conhecimento. Ainda de acordo com esses documentos, todas as turmas do PROFOP ofertadas devem possuir a carga horária total de 800 horas, em que 100 horas são destinadas ao estágio curricular obrigatório e 700 às disciplinas (500 horas são de atividades teóricas e 200 horas de atividades práticas), que se organizam por meio do Núcleo Contextual, Estrutural e Integrador, tal como prescrito pela resolução CNE/CP n. 02/1997.

Assim, a formação recebida pelos egressos do PROFOP que poderão ministrar matemática na educação básica é composta pela carga horária de matemática (mínimo de 160 horas cursadas em disciplinas correspondentes à área de matemática) proveniente da primeira graduação do egresso, a carga horária das disciplinas do Núcleo Contextual, Estrutural e Integrador e as 100 horas de estágio supervisionado obrigatório. Esses serão os objetos principais da discussão desenvolvida na sequência.

O Núcleo Contextual do PROFOP é composto por oito disciplinas, cujos títulos e ementários estão dispostos no Quadro 1.

Conforme o conteúdo das ementas explicita, nenhuma das disciplinas contempla tópicos que podem ser associados diretamente à matemática e/ou ao seu ensino - considerando as dimensões do conhecimento do professor PK, MK 
Quadro 1-Ementas das disciplinas pertencentes ao núcleo contextual.

\begin{tabular}{|c|c|}
\hline Disciplina & Conteúdos \\
\hline $\begin{array}{l}\text { Fundamentos da } \\
\text { educação }\end{array}$ & $\begin{array}{l}\text { Bases históricas, filosóficas e sociológicas da educação. Educação brasileira } \\
\text { contemporânea: limites e possibilidades. Tendências pedagógicas do Brasil. } \\
\text { Concepção de homem e de educação. A relação entre Estado, educação e trabalho. }\end{array}$ \\
\hline $\begin{array}{l}\text { Gestão } \\
\text { educacional }\end{array}$ & $\begin{array}{l}\text { Teorias da administração e gestão educacional. Escola, gestão e projeto político. } \\
\text { Estudo analítico das políticas educacionais no Brasil. A política educacional } \\
\text { no contexto das políticas públicas; impasses e perspectivas das políticas atuais } \\
\text { em relação à educação. Organizações dos sistemas de ensino considerando as } \\
\text { peculiaridades nacionais e os contextos internacionais. }\end{array}$ \\
\hline $\begin{array}{l}\text { Teoria } \\
\text { de currículo }\end{array}$ & $\begin{array}{l}\text { Conhecimentos cotidianos e escolares. Conhecimento escolar e competências: seleção } \\
\text { e distribuição. Currículo e sociedade. Currículo e ideologia. Currículo e relações de } \\
\text { poder. Currículo oculto. Perspectivas e propostas curriculares de diferentes sistemas de } \\
\text { educação, níveis de ensino e escolas. O currículo no cotidiano da escola pública. }\end{array}$ \\
\hline Oficinas I & $\begin{array}{l}\text { Espaço interdisciplinar de estudos da prática pedagógica, visando à análise global e } \\
\text { crítica da realidade educacional. Debates com diversos profissionais buscando uma } \\
\text { compreensão mais ampla da prática pedagógica. }\end{array}$ \\
\hline $\begin{array}{l}\text { Psicologia da } \\
\text { educação }\end{array}$ & $\begin{array}{l}\text { As principais teorias da psicologia aplicadas à educação escolar. Processos } \\
\text { psicológicos da aprendizagem, psicologia do desenvolvimento. Reflexão sobre temas } \\
\text { contemporâneos do campo da educação. }\end{array}$ \\
\hline $\begin{array}{l}\text { Cotidiano } \\
\text { escolar }\end{array}$ & $\begin{array}{l}\text { As relações entre professor e aluno, professor e escola, escola e família, e suas } \\
\text { implicações no contexto educacional. } \\
\text { A origem, as causas e os desdobramentos dos conflitos na escola. } \\
\text { O papel do professor e da escola em relação às drogas e às dependências químicas. }\end{array}$ \\
\hline $\begin{array}{l}\text { Profissão } \\
\text { professor }\end{array}$ & $\begin{array}{l}\text { A constituição da profissão professor. O desenvolvimento profissional docente e } \\
\text { prática pedagógica. A ética do professor no trabalho. }\end{array}$ \\
\hline Oficinas II & $\begin{array}{l}\text { Espaço interdisciplinar de estudos da prática pedagógica, visando à análise global e } \\
\text { crítica da realidade educacional. Debates com diversos profissionais buscando uma } \\
\text { compreensão mais ampla da prática pedagógica. }\end{array}$ \\
\hline
\end{tabular}

Fonte: Universidade Tecnológica Federal do Paraná (2012).

Elaboração dos autores.

e PCK apresentadas por Shulman $(1986,1987)$ e situadas no contexto particular do professor de matemática, por meio do MTSK (Carrillo-Yañez et al., 2018). Ou seja, as disciplinas do Núcleo Contextual do PROFOP abarcam conhecimentos de natureza exclusivamente pedagógica (PK), como é o caso das disciplinas oficinas I e II e profissão professor, cuja maioria dos conhecimentos pode ser associada ao General Pedagogical Knowledge, da disciplina psicologia da educação, cujos conhecimentos se associam ao Knowledge of Learners and their Characteristics (como seja), da disciplina cotidiano escolar, cuja natureza pode ser vinculada ao Knowledge of Educational Contexts, ou das disciplinas fundamentos da educação, gestão educacional e teoria de currículo, que se associam diretamente ao Knowledge of Educational ends, Purposes, and Values, and their Philosophical and Historical Grounds.

Contudo, essa composição das disciplinas incluídas no Núcleo Contextual (Quadro 1) está em consonância com o artigo $3^{\circ}$ da resolução $\mathrm{CNE} / \mathrm{CEB}$ n. 02/1997, que prescreve a necessidade desse núcleo ser estruturado visando 
à compreensão do processo de ensino-aprendizagem referido à prática de escola, considerando tanto as relações que se passam no seu interior, com seus participantes, quanto as suas relações, como instituição, com o contexto imediato e o contexto geral onde está inserida. (Brasil, 1997, p. 1)

No que se refere ao Núcleo Estrutural do PROFOP, sua composição apresenta-se de acordo com as disciplinas expostas no Quadro 2.

\section{Quadro 2 - Quadro das ementas das disciplinas pertencentes ao Núcleo Estrutural.}

\begin{tabular}{|l|l|}
\hline Disciplina & \multicolumn{1}{c|}{ Conteúdos } \\
\hline $\begin{array}{l}\text { Metodologia } \\
\text { da pesquisa em } \\
\text { educação }\end{array}$ & $\begin{array}{l}\text { A ciência e a produção do conhecimento. A pesquisa em educação: abordagens, } \\
\text { tipos e orientações metodológicas. Normas e organização do texto científico. }\end{array}$ \\
\hline $\begin{array}{l}\text { Tecnologias } \\
\text { da educação e } \\
\text { comunicação }\end{array}$ & $\begin{array}{l}\text { O uso das TIC no processo ensino-aprendizagem. Implicações do uso das } \\
\text { TIC na educação. Integração das diferentes tecnologias existentes no processo } \\
\text { de ensino. Teorias e estratégias de aprendizagem. Visão histórica das TIC na } \\
\text { educação. Construção do conhecimento por meio do uso de TIC. }\end{array}$ \\
\hline $\begin{array}{l}\text { Processos } \\
\text { de ensino e } \\
\text { aprendizagem }\end{array}$ & $\begin{array}{l}\text { A relação professor e aluno no contexto da sala de aula. A instituição escolar, } \\
\text { a relação pedagógica e o papel do professor. A aula e a atuação docente: } \\
\text { fundamentos do trabalho pedagógico. Estratégias de ensino-aprendizagem. } \\
\text { Planejamento e avaliação. }\end{array}$ \\
\hline $\begin{array}{l}\text { Educação inclusiva } \\
\text { e diversidade }\end{array}$ & $\begin{array}{l}\text { Educação inclusiva e a diversidade como referência para repensar as construçães } \\
\text { políticas e legais. O desafio da desigualdade social e educacional. A mudança } \\
\text { dos paradigmas, a inclusão e as reformas da escola. Pessoas com necessidades } \\
\text { educacionais especiais. }\end{array}$ \\
\hline Libras I & $\begin{array}{l}\text { Aspectos educacionais e socioantropológicos da surdez. A Língua de Sinais } \\
\text { Brasileira - Libras. Prática de Libras: o alfabeto; expressões manuais e não } \\
\text { manuais. Diálogos curtos com vocabulário básico, conversação com frases simples } \\
\text { e adequação do vocabulário para situações informais. }\end{array}$ \\
\hline Libras II & $\begin{array}{l}\text { Aspectos linguísticos: noções básicas de léxico, fonologia, morfologia e sintaxe da } \\
\text { língua de sinais. Criar oportunidades para a prática de conversação em Libras em } \\
\text { situaçoses formais e informais. Ampliar conhecimento dos aspectos da cultura e } \\
\text { identidade surda. }\end{array}$ \\
\hline $\begin{array}{l}\text { Espaço interdisciplinar de estudos da prática pedagógica, visando à análise global } \\
\text { e crítica da realidade educacional. Debates com diversos profissionais buscando } \\
\text { uma compreensão mais ampla da prática pedagógica. }\end{array}$ \\
\hline
\end{tabular}

Fonte: Universidade Tecnológica Federal do Paraná (2011b).

Elaboração dos autores.

Como discriminado do Quadro 2, nenhuma das disciplinas ofertadas no âmbito do Núcleo Estrutural do PROFOP refere-se à matemática e, por conseguinte, não se associa aos domínios e subdomínios MK e PCK, uma vez que focam sua atenção integralmente nas dimensões do PK. Aqui, novamente, o objeto essencial da prática do professor de matemática, o ensino da matemática (Carrillo-Yañez et al., 2018), não é contemplado no processo formativo. Ou seja, nenhuma das disciplinas veicula por meio de sua ementa o desenvolvimento de elementos do conhecimento 
especializado do professor de matemática e, portanto, deixa à margem, por exemplo, o significado de conceitos e exemplos que caracterizam os tópicos matemáticos a serem abordados nas aulas dessa área do conhecimento na educação básica ou o conteúdo disciplinar da matemática abordado por livros-textos e demais materiais de cunho pedagógico (KoT). Além disso, não são discutidas possibilidades de estabelecimento de conexões entre conceitos e elementos da matemática, de modo que permita que o futuro professor de matemática compreenda e seja capaz de ensinar certos conceitos matemáticos avançados desde uma perspectiva elementar e desenvolver determinados conceitos elementares com base em uma perspectiva avançada (que seriam elementos centrais do KSM). Também não são explorados aspectos relacionados ao pensamento matemático, como o conhecimento relativo às diferentes formas de definir, argumentar ou demonstrar em matemática, bem como o conhecimento da sintaxe matemática (KPM). Da mesma forma, não são discutidas, no decorrer do PROFOP, distintas estratégias de ensino da matemática, mesmo sendo um recurso que vai permitir ao professor fomentar o desenvolvimento das capacidades matemáticas procedimentais e conceituais (KMT) dos estudantes, nem o conhecimento das características do processo de compreensão dos diferentes conteúdos matemáticos pelos estudantes, os erros, dificuldades e obstáculos associados a cada conceito e a linguagem usada pelos estudantes em relação ao conceito trabalhado em sala de aula (KFLM) e o conhecimento do currículo adotado pela instituição onde atua para ser trabalhado em todas as etapas/níveis de ensino da matemática (KMLS).

Assim, ao nos reportarmos ao artigo $3^{\circ}$ da resolução CNE/CEB n. 02/1997, que versa sobre a composição do Núcleo Estrutural, temos que, por meio desse núcleo, deveriam ser abordados os "conteúdos curriculares, sua organização sequencial, avaliação e integração com outras disciplinas, os métodos adequados ao desenvolvimento do conhecimento em pauta, bem como sua adequação ao processo de ensino-aprendizagem" (Brasil, 1997, p. 1). Entretanto, conforme discutido nos parágrafos anteriores, a matemática e os processos de seu ensino e aprendizagem não figuram nas ementas do Núcleo Estrutural. Portanto, é possível aferirmos que existe um distanciamento entre a prescrição estabelecida pela resolução e a implementação desenvolvida pela IES, uma vez que tal núcleo de conhecimentos deveria voltar-se para os processos intrínsecos e específicos da matemática e do seu ensino na educação básica.

O Núcleo Integrador do PROFOP é constituído apenas pela disciplina "Seminários de Estudos Pedagógicos", que é composta pelos seguintes conteúdos: responsabilidade socioambiental e sustentabilidade; educação profissional; educação a distância; educação de jovens e adultos; educação no campo; prevenção ao uso de drogas; tecnologias assistivas; empreendedorismo e empregabilidade; fundamentos teórico-metodológicos das ciências: naturais, humanas e sociais; sexualidade e implicações. Conforme podemos observar, nenhum dos tópicos associa-se à matemática.

Diante do exposto, é possível afirmar que no decorrer do processo formativo de professores de matemática promovido pelas disciplinas do PROFOP não são veiculados conhecimentos associados à área de atuação futura desses profissionais, a matemática, e são trabalhados conteúdos vinculados unicamente ao PK (Shul- 
man, 1986, 1987). Assim, a não vinculação, relação e interação da dimensão dos conhecimentos pedagógicos com os conhecimentos matemáticos, especialmente os veiculados pelo currículo escolar, e com os conhecimentos sobre as aprendizagens matemáticas (e dificuldades) dos estudantes (como os erros comumente cometidos), os recursos de ensino da matemática (como o livro didático, por exemplo) e a escola, torna o conteúdo pedagógico presente no processo formativo do professor inerte em relação à aprendizagem matemática (Moreira, 2012).

Ademais, essa não vinculação entre as dimensões do conhecimento pedagógico e o conhecimento matemático do professor afasta-se consideravelmente dos resultados obtidos por diversas pesquisas (essencialmente internacionais) que investigam a relação entre o conhecimento especializado do professor de matemática (Ball, Thames e Phelps, 2008; Baumert e Kunter, 2013; Bromme, 1993; Carrillo-Yañez et al., 2018; Kaiser et al., 2017; Pino-Fan, Assis e Castro, 2015; Rowland e Turner, 2007; Schoenfeld e Kilpatrick, 2008) e a qualidade do ensino dessa área do conhecimento no ambiente escolar.

Esse cenário, quando associado ao histórico da formação do professor de matemática desenvolvida no Brasil, configura-se como uma nova vertente formativa, que em vez de propalar uma formação pautada na quebra da hegemonia do modelo “3+1” (Moreira e David, 2005; Saviani, 2009; Moreira, 2012; Barreto, 2015), por meio de uma integração entre a dimensão pedagógica e a relacionada ao conteúdo (matemático) (Oliveira e Fiorentini, 2018), pauta seu processo formativo única e exclusivamente na formação pedagógica (PK).

Para efeito de discussão da problemática da não vinculação entre a dimensão do conhecimento pedagógico e do conhecimento matemático (objeto da prática do professor de matemática), torna-se importante, de modo que explicite essa desvinculação, analisar e discutir a estrutura de algumas das disciplinas da grade curricular. Nesse sentido, nos parágrafos seguintes centraremos as discussões nas disciplinas "tecnologias da educação e comunicação" e "processos de ensino e aprendizagem".

A disciplina "tecnologias da educação e comunicação" (composta pelos conteúdos: O uso das TIC no processo ensino-aprendizagem; Implicações do uso das TIC na Educação; Integração das diferentes tecnologias existentes no processo de ensino; Teorias e estratégias de aprendizagem; Visão histórica das TIC na educação; Construção do conhecimento por meio do uso de TIC) volta-se para a discussão da articulação entre a educação e os processos de ensino e aprendizagem, mas não a relaciona ao ensino da matemática, mesmo sendo que essa última articulação que promoveria o desenvolvimento dos conhecimentos que são a base do bom ensino da matemática (Ball, Thames e Phelps, 2008; Baumert e Kunter, 2013; Bromme, 1993; Carrillo-Yañez et al., 2018; Kaiser et al.,2017; Pino-Fan, Assis e Castro, 2015; Rowland e Turner, 2007; Schoenfeld e Kilpatrick, 2008), particularmente quando desenvolvido por meio da tecnologia (Koehler e Mishra, 2009; Mishra e Koehler, 2006; Sampaio e Coutinho, 2015). Nesse cenário, como o ementário da disciplina aborda conhecimentos que podem ser relacionados ao Knowledge of Educational Contexts e ao General Pedagogical Knowledge para estar associados com o ensino de matemática (Carrillo-Yañez et al., 2018), ela deveria discutir a compreensão da representação de conceitos matemáticos considerando as tecnologias e as perspectivas 
pedagógicas que usam tecnologias de maneiras construtivas para ensinar matemática (KoT e KMT), o conhecimento do que torna os conceitos matemáticos "difíceis" ou "fáceis" de aprender e como a tecnologia pode ajudar a corrigir alguns dos problemas que os estudantes enfrentam (KFLM), e, por fim, o conhecimento de como as tecnologias podem ser usadas para explorar os conhecimentos matemáticos prévios dos alunos (KFLM e KMLS) (Carrillo-Yañez et al., 2018; Koehler e Mishra, 2009; Mishra e Koehler, 2006; Sampaio e Coutinho, 2015).

Ainda para efeito de discussão, consideremos também a disciplina "processos de ensino e aprendizagem" (composta pelos conteúdos: A relação professor e aluno no contexto da sala de aula; A instituição escolar, A relação pedagógica e o papel do professor; A aula e a atuação docente: fundamentos do trabalho pedagógico; Estratégias de ensino-aprendizagem; Planejamento e avaliação), que pode ser associada aos quatro subdomínios do PK (General Pedagogical Knowledge; Knowledge of Learners and their Characteristics; Knowledge of Educational Contexts; Knowledge of Educational ends, Purposes, and Values, and their Philosophical and Historical Grounds). Se o objetivo fosse o de buscar a promoção direta do ensino de matemática, na disciplina deveriam ser abordadas as especificidades que o ensino dessa área do conhecimento possui no ambiente escolar, como os conhecimentos matemáticos escolares que são veiculados pelo currículo escolar e como eles se relacionam no decorrer desse documento (KLMS), desenvolvendo o conhecimento do professor relativamente às conexões (KSM) e a natureza da prática de fazer matemática situada em um contexto de prática profissional docente (KPM), como eles podem ser ensinados e avaliados (KMT) nesse nível educacional de modo que maximize as aprendizagens dos alunos (KFLM).

Nessa conjuntura, incluímos no processo analítico da pesquisa a discussão sobre mais um elemento do projeto de formação do professor de matemática desenvolvido pela IES: os conhecimentos matemáticos a que os habilitados tiveram contato no curso de graduação considerado como requisito para seu ingresso no PROFOP.

De acordo com o artigo $2^{\circ}$ da resolução CNE/CB n. 02/1997, o PROFOP "é destinado a portadores de diploma de nível superior, em cursos relacionados à habilitação pretendida, que ofereçam sólida base de conhecimentos na área de estudos ligada a essa habilitação", sendo a verificação da compatibilidade entre a formação do candidato e a disciplina para a qual pretende habilitar-se é de responsabilidade da IES proponente do programa (Brasil, 1997, p. 1, grifo nosso). E a corporificação desse parecer ocorre na regulamentação interna da universidade para o PROFOP, por meio dos artigos 46 e 47 da resolução n. 28/2011 (COGEP) ao estabelecer que:

Art. 46 Aos interessados que pretendem obter certificação em disciplinas do Núcleo Comum - Matemática, Física, Biologia, Química, Língua Portuguesa e Língua Estrangeira Moderna poderão ser admitidos no Programa Especial de Formação Pedagógica desde que tenham cursado em nível de graduação uma carga horária minima de 160 horas da respectiva disciplina ou conjunto de disciplinas correspondentes à área da habilitação pretendida; 
Art. 47 Aos interessados que pretenderem obter certificação em disciplinas profissionalizantes poderão ser admitidos no Programa Especial de Formação Pedagógica se tiverem cursado graduação na área da habilitação pretendida. (UTFPR, 2012, p. 17, grifos nossos)

Assim, a partir desses critérios, foram considerados como portadores de "sólida formação" em matemática 207 egressos de 39 cursos de graduação distintos que, de acordo com o documento de "Classificação Internacional Normalizada da Educação (CINE): Áreas de Formação e Treinamento”6 (Brasil, 2017), podem ser aglutinados em sete áreas do conhecimento, conforme Gráfico 2.

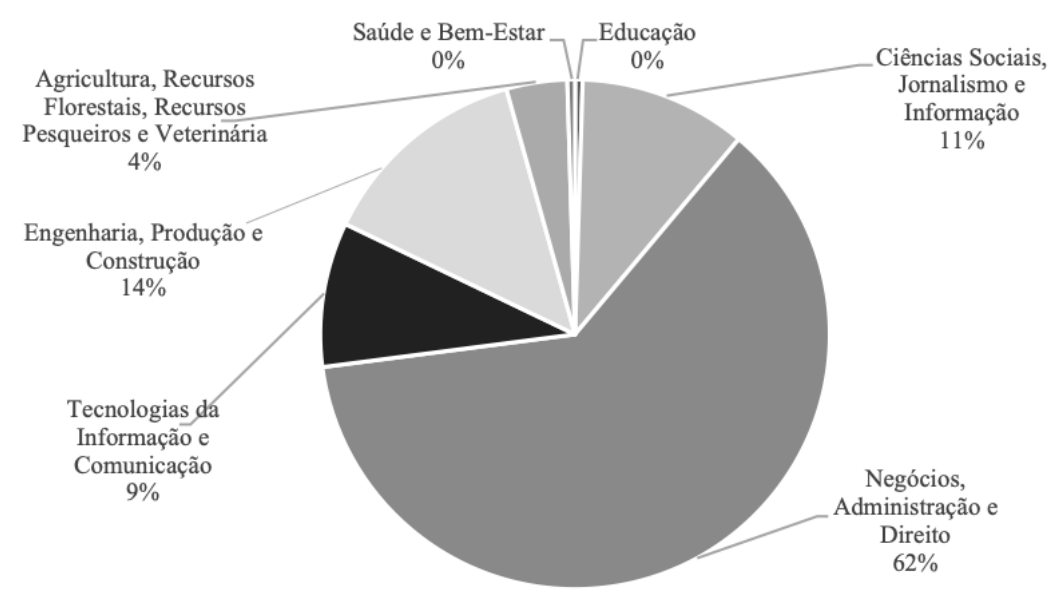

Gráfico 2 - Área do conhecimento cujos cursos foram considerados portadores de "sólida formação" em matemática.

Fonte: Banco de dados da pesquisa (2018).

Elaboração dos autores.

Tendo como parâmetro a CINE, foram aglutinados na área "Negócios, Administração e Direito" (com 128 habilitações concedidas) os cursos de administração, administração de empresas, administração com ênfase (em agronegócios, comércio exterior e marketing), além de ciências contábeis e contabilidade. Já na área de "Engenharia, Produção e Construção" (com 28 habilitações concedidas) foram concentrados os cursos de engenharias com habilitação em química, ambiental, alimentos, elétrica, eletrônica e telecomunicações, de produção, mecânica e têxtil, além dos cursos de tecnologia em processamento de dados, alimentos, automação industrial, manutenção

6 A CINE apresenta uma classificação das áreas de formação e treinamento composta por 12 áreas, a saber: Programas genéricos e certificações; Educação, Artes e Humanidades; Ciências Sociais, Jornalismo e Informação; Negócios, Administração e Direito; Ciências Naturais, Matemática e Estatística; Tecnologias da Informação e Comunicação; Engenharia, Produção e Construção; Agricultura, Recursos Florestais, Recursos Pesqueiros e Veterinária; Saúde e Bem-Estar; Serviços; Área desconhecida. 
industrial e telecomunicações e dos bacharelados em processamento de dados, química industrial e processos químicos.

Para a área de "Ciências Sociais, Jornalismo e Informação" (com 22 habilitações concedidas), foram considerados os cursos de ciências econômicas e economia, enquanto na área de "Tecnologias da Informação e Comunicação" (com 19 habilitações concedidas) foram enquadrados os cursos de análise de sistemas, ciências e engenharia da computação, sistema de informação, além das tecnologias em desenvolvimento de sistema de informação e informática.

$\mathrm{Na}$ área de "Agricultura, Recursos Florestais, Recursos Pesqueiros e Veterinária" (com oito habilitações concedidas), foram inseridos os cursos de agronomia, zootecnia, tecnologias em agronegócio e gestão ambiental e engenharias florestal e da pesca. Ao passo que na área de "Saúde e Bem-Estar" foi concedida apenas uma habilitação, por meio do curso de tecnólogo em radiologia, e na área de Educação também apenas uma habilitação foi concedida, para um licenciado em física.

Com base na interpretação dos dados anteriormente elucidados, podemos constatar que foram considerados pela IES, no processo de habilitação, como cursos portadores de "uma sólida formação em matemática" 39 graduações distintas, que pertencem a sete diferentes áreas do conhecimento. E, além disso, de acordo com a CINE (Brasil, 2017), nenhum desses cursos figura na área do conhecimento "Ciências Naturais, Matemática e Estatística", que congrega os cursos correlatos à matemática.

Nesse cenário, o primeiro elemento a ser discutido refere-se ao conjunto de conhecimentos matemáticos (conteúdo) que são disseminados (forma) por meio desses cursos de graduação, que são diretamente direcionados para prática profissional de cada um desses especialistas. Ou seja, a formação matemática (conhecimento) obtida pelo engenheiro está (ou deveria estar) diretamente associada às exigências de sua prática profissional, do mesmo modo que na formação dos demais profissionais. Entretanto, essas especificidades da formação matemática associadas à atuação profissional parecem ser deixadas à margem no processo formativo desenvolvido no âmbito do PROFOP em relação ao professor de matemática.

Nesse sentido, a formação matemática dos profissionais egressos dos 39 cursos superiores mencionados concentra-se, geralmente, apenas em alguns elementos associados ao saber fazer, classificados por Carrillo-Yañez et al. (2018) como pertencentes ao subdomínio KoT (ou seja, focam na abordagem de definições, propriedades e procedimentos matemáticos vinculados à aplicação dessa área do conhecimento na manipulação de problemas característicos de cada uma dessas áreas - engenharia, administração, economia etc.). Contudo, nesses cursos não são abordadas, por exemplo, as distintas representações e aplicações que um conhecimento matemático pode assumir, que formam parte das especificidades do conhecimento matemático do professor (ainda no âmbito do KoT), as distintas formas de validação e demonstração, o papel dos símbolos e da linguagem formal adotada pela matemática, as condições necessárias e suficientes para serem geradas definições matemática (KPM), as conexões (de complementação, simplificação, transversais e auxiliares) entre os diferentes tópicos (KSM) e a natureza das áreas 
de matemática (e a correspondente sequenciação) que compõem os documentos oficiais escolares (KMLS).

Para efeito de discussão (e exemplificação), e considerando que, ao longo das 19 turmas do PROFOP, o número de formados dos diferentes grupos difere estatisticamente entre si ( $\mathrm{p}$-valor $<0,05, \mathrm{~F}=75,79)$ e que o número médio de formados da área de Administração éconsideravelmente superior aos demais $(\mathrm{p}<0,05)$, doravante nos deteremos na discussão de elementos que compõem a formação matemática dos profissionais egressos de cursos da área de Administração.

De acordo com Braga et al. (2011, p. 6), a estrutura curricular dos cursos da área de Administração é composta pelas disciplinas "fundamentos de matemática elementar", "cálculo diferencial e integral", "estatística e probabilidade" e "matemática financeira”. A partir dessa sucinta descrição, é possível apontar pelo menos três falhas consideráveis.

A primeira delas refere-se à ausência na formação matemática adquirida pelo administrador de conhecimentos prescritos pelo currículo escolar, como é o caso das geometrias (euclidiana plana, espacial e analítica), limitando o egresso do PROFOP a ensinar pautado quase que exclusivamente no que aprendeu quando aluno da educação básica, uma vez que não teve oportunidade de discutir as diferentes dimensões que essa área do conhecimento possui quando associada à prática docente, como o MK e o PCK (Carrillo-Yañez et al., 2018).

Ainda nesse contexto, consideremos um conhecimento matemático que figura tanto no currículo escolar (Brasil, 1998) (KoT) quanto na ementa das disciplinas de "cálculo diferencial e integral" dos cursos de administração (Braga et al., 2011), a saber, esse tema é "funções". Assim, em um primeiro plano, a formação do administrador em relação ao tema "funções" poderia ser associada diretamente à prática do professor de matemática da educação básica. Contudo, o conceito de função veiculado por essa disciplina está intimamente vinculado aos conceitos de limite, continuidade, derivada e integral, que não são objeto da prática do professor na educação básica e cuja abordagem nos cursos de administração não estabelece conexões com a abordagem das "funções" que é feita na educação básica, e por conseguinte não discute elementos do MK e do PCK, que são suscitados na prática do professor de matemática ao ensinar "funções" no ensino médio, por exemplo (Carrillo-Yañez et al., 2018).

O segundo elemento formativo que interfere na prática docente e emana, entre outros contextos, também dos cursos de graduação frequentados - no caso, dos cursos mencionados no Gráfico 2 - refere-se às crenças sobre a matemática (vista de uma perspectiva essencialmente instrumentalista) e seu ensino (essencialmente tradicional), que limitam a prática do professor, já que não estão associadas, por exemplo, ao processo de criação da matemática e de uma abordagem com vistas a tornar o aluno um sujeito autônomo (em seu processo de aprendizagem). No entanto, são essas associações que permitem ao professor, por exemplo, ensinar o conteúdo de forma conectada (com demais áreas do conhecimento e com os diversos domínios da própria matemática) e validar as conjecturas matemáticas de seus alunos (Carrillo-Yañez et al., 2018).

A terceira ausência latente na formação matemática proveniente dos elementos formativos dos 39 cursos de graduação nominados relaciona-se aos 
conhecimentos vinculados à prática de idealizar e promover o ensino de matemática, ao desenvolvimento e seleção de tarefas/atividades matemática, à seleção e elaboração de representações e explicações de conceitos/propriedades matemáticos, à interpretação e compreensão das produções dos estudantes, dos livros didáticos e demais materiais vinculados ao currículo escolar (Ball, Thames e Phelps, 2008; Baumert e Kunter, 2013; Carrillo-Yañez et al., 2018; Kaiser et al., 2017; Pino-Fan, Assis e Castro, 2015; Scheiner et al., 2017; Schoenfeld e Kilpatrick, 2008; Zakaryan e Ribeiro, 2018), ou seja, a ausência dos elementos relacionados estreitamente ao PCK (e subdomínios). Essa ausência é notória e irrefutável, uma vez que a natureza dos conhecimentos que compõem o PCK está unicamente vinculada à prática profissional do professor e, por conseguinte, não é objeto da formação inicial dos demais profissionais.

\section{CONSIDERAÇÕES FINAIS}

No decorrer das análises, construímos um panorama do projeto de formação de professores de matemática empreendida pelo PROFOP, tendo como base o estudo de um caso de implementação dessa política nacional de formação de professores.

A análise das ementas das disciplinas evidenciou a supervalorização dos conhecimentos de natureza estritamente pedagógica $(\mathrm{PK})$ e a ausência latente das dimensões formativas relativas à matemática (MK e PCK) no decorrer da capacitação desenvolvida pelo PROFOP. Assim, a compreensão dos conteúdos matemáticos proveniente da habilitação concedida via PROFOP pauta-se única e exclusivamente nos conhecimentos provenientes da primeira graduação dos egressos do PROFOP e na parca carga horária destinada ao estágio supervisionado que, em tese, deveria ocorrer nas aulas de matemática ministradas na educação básica. No entanto, de maneira geral, essa formação abarca apenas uma pequena parcela dos conteúdos que figuram no currículo escolar. Além disso, não se identificam, em todo o processo formativo desenvolvido no contexto do PROFOP, situações voltadas à construção, pelos professores em formação, de elementos que figuram nos subdomínios do PCK. Desse modo, é possível afirmar que os egressos desse modelo de formação possuem graves lacunas formativas em relação aos conhecimentos que realmente amparam a prática do professor ao ensinar matemática na educação básica tendo em vista aprendizagens matemáticas efetivas pelos estudantes.

Ademais, no decorrer da análise desenvolvida, ficou claro que o projeto de formação de professores de matemática promovido pela IES por meio do PROFOP considera esse processo como um simples conglomerado de vários campos de conhecimento, que podem ser construídos desvinculados e não relacionados, contrariando fortemente os resultados provenientes de pesquisas desenvolvidas no âmbito do reconhecimento e identificação do conhecimento do professor de matemática (Ball, Thames e Phelps, 2008; Baumert e Kunter, 2013; Bromme, 1993; Carrillo-Yañez et al., 2018; Kaiser et al., 2017; Pino-Fan, Assis e Castro, 2015; Rowland e Turner, 2007; Schoenfeld e Kilpatrick, 2008). O processo formativo desenvolvido pela IES, quando visto sob a lógica da soma de conteúdos e conhecimentos peda- 
gógicos, de acordo com Shulman $(1986,1987)$, associa-se muito mais à formação do pedagogo do que à formação do professor de matemática.

Diante disso, podemos afirmar que o processo formativo descontínuo privilegiado pelo PROFOP, que pressupõe que a qualificação do professor pode ser promovida apenas pela formação didático-pedagógica técnica e formal desconectada da área de conhecimento que o professor egresso irá trabalhar na educação básica, no caso a matemática, distancia-se das prescrições jurídicas vigentes. Ou seja, a universidade federal, ao implementar o PROFOP, não cumpriu todas as exigências estabelecidas pela resolução CNE/CEB n. 02/1997 e documentos derivados dela.

Nesse contexto, o PROFOP parece reforçar e aprimorar a tradicional cisão entre a "forma e o conteúdo"(Fiorentini e Oliveira, 2018; Moreira, 2012; Moreira e David, 2005; Saviani, 2009), na medida em que, além de não promover um mínimo de articulação entre essas duas dimensões do conhecimento do professor, sequer oportuniza a seus egressos momentos formativos vinculados à matemática. Melhor dizendo, esmera a polarização dos conhecimentos, em que a dimensão pedagógica foi supervalorizada em relação à dimensão matemática.

\section{REFERÊNCIAS}

ANDRÉ, M.E. D. A. Formação de professores: a constituição de um campo de estudos. Educação, Porto Alegre, v. 33, n. 3, p. 174-181, 2010.

BALL, D. L.; THAMES, M. H.; PHELPS, G. Content knowledge for teaching: what makes it special? Journal of Teacher Education, Nova York, v. 59 n. 5, p. 389-407, 2008. http://dx.doi.org/10.1177/0022487108324554

BARRETTO, E. S. S. Políticas de formação docente para a educação básica no Brasil: embates contemporâneos. Revista Brasileira de Educação, Rio de Janeiro, v. 20, n. 62, p. 679-701, jul./set. 2015. http://dx.doi.org/10.1590/S141324782015206207

BAUMERT, J.; KUNTER, M. The COACTIV model of teachers' professional competence. In: KUNTER, M. et al. (eds.). Cognitive activation in the mathematics classroom and professional competence of teachers, mathematics teacher education. Nova York: Springer, 2013. p. 25-48.

BRAGA, G. B.; OLHER, B. S.; REIS, F. N. C.; OLIVEIRA, A. R. Análise da formação curricular dos cursos de administração oferecidos por instituições federais na Zona da Mata Mineira à luz da resolução CNE/CES n. 4, de 13 de julho de 2005. Revista Administração em Diálogo, São Paulo, v. 13, n. 3, p. 56-68, 2011. https://doi. org/10.20946/rad.v13i3.7796

BRASIL. Lei n. 9.394, de 20 de dezembro de 1996. Estabelece as Diretrizes e Bases da Educação Nacional. Brasília, DF: Congresso Nacional, 1996.

BRASIL. Resolução n. 2, de 26 de fevereiro de 1997. Dispõe sobre os programas especiais de formação pedagógica de docentes para as disciplinas do currículo do ensino fundamental, do ensino médio e da educação profissional em nível médio. Brasília, DF:

MEC/CNE, 1997. 
BRASIL. Parâmetros Curriculares Nacionais. Brasília, DF: MEC, 1998.

BRASIL. Plano Nacional de Educação. Brasília, DF: MEC/INEP, 2001.

BRASIL. Conselho Nacional de Educação. Resolução CNE/CP 1, de 18 de fevereiro de 2002. Institui Diretrizes Curriculares Nacionais para a Formação de Professores da Educação Básica, em nível superior, curso de licenciatura, de graduação plena. Brasília, DF: MEC/CNE, 2002a.

BRASIL. Resolução CNE/CP 2, de 19 de fevereiro de 2002. Institui a duração e a carga horária dos cursos de licenciatura, de graduação plena, de formação de professores da Educação Básica em nível superior. Brasília, DF: MEC/CNE, 2002b.

BRASIL. Parecer CNE/CP n. 25/2002, de 3 de setembro de 2002. Brasília, DF: MEC/CNE, 2002c.

BRASIL. Resolução CNE/CES n. 3, de 18 de fevereiro de 2003. Estabelece as Diretrizes Curriculares para os cursos de Matemática. Brasília, DF: MEC/CNE, 2003.

BRASIL. Resolução n. 2, de $\mathbf{1}^{\circ}$ de julho de 2015. Define as Diretrizes Curriculares Nacionais para a formação inicial em nível superior (cursos de licenciatura, cursos de formação pedagógica para graduados e cursos de segunda licenciatura) e para a formação continuada. Brasília, DF: MEC/CNE, 2015.

BRASIL. Classificação Internacional Normalizada da Educação (CINE): áreas de formação e treinamento. Brasília, DF: MEC/INEP, 2017.

BROMME, R. Beyond subject matter: a psychological topology of teachers' professional knowledge. In: BIEHLER, R.; SCHOLZ, R.W.; STRÄßER, R.; WINKELMANN, $B$. Mathematics didactics as a scientific discipline. The state of the art. Dordrecht: Kluwer, 1993. p. 73-88.

CALDATTO, M. E.; PAVANELLO, R. M. Um panorama histórico do ensino de geometria no Brasil: de 1500 até os dias atuais. Quadrante, Lisboa, v. 24, n. 1, p. 103$128,2015$.

CARRILLO-YAÑEZ, J.; CLIMENT, N.; MONTES, M.; CONTRERAS, L. C.; FLORES, E.; ESCUDERO, D. et al. The Mathematics Teacher's Specialised Knowledge (MTSK) Model. Research in Mathematics Education, Londres, v. 20, n. 3, p. 236-253, 2018. https://doi.org/10.1080/14794802.2018.1479981

CHARALAMBOUS, C. Y.; LITKE, E. Studying instructional quality by using a content-specific lens: the case of the mathematical quality of instruction framework. ZDM, Switzerland, v. 50, n. 3, p. 445-460, 2018.

COSTA, G. G. O. Estatística aplicada à educação com abordagem além da análise descritiva: teoria e prática. Rio de Janeiro: Editora Ciência Moderna, 2015.

FIORENTINI, D. A pesquisa e as práticas de formação de professores de matemática em face das políticas públicas no Brasil. Bolema, Rio Claro, v. 21, n. 29 , p. 43-70, 2008.

GATTI, B. A. Formação inicial de professores para a educação básica: pesquisas e políticas educacionais. Estudos em Avaliação Educacional, São Paulo, v. 25, n. 57, p. 24-54, 2014. http://dx.doi.org/10.18222/eae255720142823 
GATTI, B. A.; BARRETTO, E. S. Professores do Brasil: impasses e desafios. Brasília, DF: UNESCO, 2009.

GATTI, B. A.; BARRETTO, E. S.; ANDRÉ, M. E. D. A. Políticas docentes no Brasil: um estado da arte. Brasília, DF: UNESCO, 2011.

HILL, H. C.; BALL, D. L. The curious - and crucial - case of Mathematical Knowledge for Teaching. Phi Delta Kappan, Thousand Oaks, v. 91, n. 2, p. 68-71, 2009. https://doi.org/10.1177/003172170909100215

KAISER, G.; BLÖMEKE, S.; KÖNIG,J.; BUSSE, A.; DÖHRMANN, M.; HOTH, J. Professional competencies of (prospective) mathematics teachers - cognitive versus situated approaches. Educational Studies in Mathematics, Switzerland, v. 94, p. 161182, 2017. https://doi.org/10.1007/s10649-016-9713-8

KOEHLER,M.J.; MISHRA, P.What is technological pedagogical content knowledge? Contemporary issues in technology and teacher education, San Diego, v. 9, n. 1, p. 60-70, 2009.

KRAUSS, S.; BLUM, W. The conceptualisation and measurement of pedagogical content knowledge and content knowledge in the COACTIV study and their impact on student learning. Journal of Education, Thousand Oaks, v. 56, n. 1, p. 45-65, 2013.

MARCONI, M. A.; LAKATOS, E. M. Fundamentos de metodologia científica. São Paulo: Atlas, 2017.

MISHRA, P.; KOEHLER, M. J. Technological pedagogical content knowledge: a framework for integrating technology in teacher knowledge. Teachers College Record, Nova York, v. 108, n. 6, p. 1.017-1.054, 2006.

MOREIRA, P. C. $3+1$ e suas (in)variantes (Reflexões sobre as possibilidades de uma nova estrutura curricular na licenciatura em matemática). Bolema, Rio Claro, v. 26, n. 44, p. 1.137-1.150, 2012. https://doi.org/10.1590/S0103-636X2012000400003

MOREIRA, P. C.; DAVID, M. M. M. S. O conhecimento matemático do professor: formação e prática docente na escola básica. Revista Brasileira de Educação, Rio de Janeiro, n. 28, p. 50-61, 2005. http://dx.doi.org/10.1590/S141324782005000100005

NACARATO, A. M. A parceria universidade-escola: utopia ou possibilidade de formação continuada no âmbito das políticas públicas? Revista Brasileira de Educação, Rio de Janeiro, v. 21, n. 66, p. 699-716, jul./set. 2016. https://doi.org/10.1590/S141324782016216636

OLIVEIRA, A. T. C. C.; FIORENTINI, D. O papel e o lugar da didática específica na formação inicial do professor de matemática. Revista Brasileira de Educação, Rio de Janeiro, v. 23, e230020, p. 1-17, 2018. http://dx.doi.org/10.1590/s141324782018230020

PINO-FAN, L.; ASSIS, A.; CASTRO, W. F. Towards a methodology for the characterization of teachers' didactic-mathematical knowledge. Eurasia Journal of Mathematics, Science, \& Technology Education, Londres, v. 11, n. 6, p. 1.429-1.456, 2015. https://doi.org/10.12973/eurasia.2015.1403a 
ROWLAND, T.; TURNER, F. Developing and using the "knowledge quartet": a framework for the observation of mathematics teaching. The Mathematics Educator, Athens, v. 10, n. 1, p. 107-123, 2007.

SAMPAIO, P.A. S. R.; COUTINHO, C.P. O professor como construtor do currículo: integração da tecnologia em atividades de aprendizagem de matemática. Revista Brasileira de Educação, Rio de Janeiro, v. 20, n. 62, p. 635-661, jul./set. 2015. https:// doi.org/10.1590/S1413-24782015206205

SANTOS, A. R. Metodologia científica: a construção do conhecimento. 7. ed. Rio de Janeiro: DP\&A, 2007.

SAVIANI, D. Formação de professores: aspectos históricos e teóricos do problema no contexto brasileiro. Revista Brasileira de Educação, Rio de Janeiro, v. 14, n. 40, p. 143155, jan./abr. 2009. https://doi.org/10.1590/S1413-24782009000100012

SCHEINER, T.; MONTES, M. A.; GODINO, J. D.; CARRILLO, J.; PINOFAN, L. R. What makes mathematics teacher knowledge specialized? Offering alternative views. International Journal of Science and Mathematics Education, Switzerland, v. 17, n. 1, p. 153-172, 2017. https://doi.org/10.1007/s10763-0179859-6

SCHOENFELD, A.H.; KILPATRICK, J. Toward a theory of proficiency in teaching mathematics. In: TIROSH, D.; WOOD, T. (eds.). International handbook of mathematics teacher education: volume 2. Rotterdam: The Netherlands, 2008. p. 321-354. https://doi.org/10.1163/9789087905460_016

SHULMAN, L. S. Those who understand: knowledge growth in teaching. Educational Researcher, Thousand Oaks, v. 15, n. 2, p. 4-14, 1986.

SHULMAN, L. S. Knowledge and teaching: foundations of the new reform.Harvard Educational Review, Cambridge, v. 57, n. 1, p. 1-22, 1987.

UTFPR - Universidade Tecnológica Federal do Paraná. Resolução n. 28/11 COGEP. Dispõe sobre o Regulamento do Programa Especial de Formação Pedagógica - PROFOP/PARFOR da UTFPR. Curitiba: UTFPR, 2011a.

UTFPR - Universidade Tecnológica Federal do Paraná. Resolução n. 29/11 COGEP. Dispõe sobre as Orientações para a Elaboração do Projeto de Abertura de Turma - PROFOP da UTFPR. Curitiba: UTFPR, 2011b.

UTFPR - Universidade Tecnológica Federal do Paraná. Resolução n. 72/12 COGEP. Dispõe sobre o Regulamento do Programa Especial de Formação Pedagógica - PROFOP/PARFOR da UTFPR. Curitiba: UTFPR, 2012.

ZAKARYAN, D.; RIBEIRO, M. Mathematics teachers' specialized knowledge: a secondary teacher's knowledge of rational numbers. Research in Mathematics Education, London, v. 21, n. 1, p. 25-42, 2018. https://doi.org/10.1080/14794802.2 018.1525422

ZOCOLOTTI, A. K. Concepções sobre os processos de ensino e de aprendizagem de matemática: um estudo de caso com professores graduados em áreas afins. 2015. 147 f. Tese (Doutorado em Educação Matemática) — Pontifícia Universidade Católica de São Paulo, São Paulo, 2015. 


\section{SOBRE OS AUTORES}

Marlova Estela Caldatto é doutora em educação para a ciência e a matemática pela Universidade Estadual de Maringá (UEM). Professora da Universidade Tecnológica Federal do Paraná (UTFPR).

E-mail: maracaldatto@yahoo.com.br

Carlos Miguel Ribeiro é doutor em pesquisa em ensino e aprendizagem de ciências experimentais pela Universidad de Huelva (Espanha). Professor da Universidade Estadual de Campinas (UNICAMP).

E-mail: cmribas78@gmail.com

Recebido em 9 de março de 2019

Aprovado em 18 de fevereiro de 2020 